\title{
$\mathrm{PDA}$ 화면 내 버튼 선택을 위한 입력지원방식의 사용성 평가
}

\author{
박용성* · 한성호* · 문정태* 전석희**
}

\section{Usability Evalulation of Button Selection Aids for PDAs}

\author{
Yong S. Park , Sung H. Han*, Jungtae Moon ${ }^{*}$, Sukhee Jeon ${ }^{* *}$
}

\begin{abstract}
The primary objective of this study is to design input methods for assisting button selection tasks on a PDA screen. Familiar methods in the existing computing environments were investigated to develop aiding methods. Factors manipulated in the experiment included aiding method, button size, and users' prior experience with PDAs. A total of sixteen participants examined the usability of button selection tasks. Two types of button selection tasks were used as experimental tasks; one was selecting a target button, and the other was selecting multiple target buttons consecutively. The results showed that the aiding method and the button size had significant effects on the subjective satisfaction as well as the performance. In addition, users' prior experience with PDAs affected the performance significantly. The interaction between the aiding method and the button size was found to have significant effects on the performance. However, the interaction effect between the button size and the PDA experience was significant on the task performance time only for the multiple button selection tasks. Design considerations were proposed based on the experimental results. These can be applied to the PDA interaction design to make the PDAs more usable.
\end{abstract}

Keyword: PDA interface design, Button selection tasks, Aiding methods, Usability

\section{1. 서 론}

개인정보단말기(Personal digital assistants; PDAs)는 휴대성, 이동성, 무선네트워크, 다기능성 등의 장점으로 인해 1990년대 중반 이후 널리 보급되어 사용되고 있다. 개발 초 기의 $\mathrm{PDA}$ 는 개인정보 관리에 주로 사용되었으나, 기술의 급격한 발전에 따라 $\mathrm{PDA}$ 의 사용 분야는 확대되고 있다. 앞 으로의 PDA는 정보제공, 자기개발, 상거래, 여가활동, 대외 활동 등 다양한 분야에서 폭 넓게 사용될 것이다(Marcus과 Chen, 2002).

기존의 데스크탑 환경에서는 키보드와 마우스가 입력도구
로서 널리 사용되어 왔다. 그러나 키보드와 마우스는 휴대성 이 떨어지기 때문에 $\mathrm{PDA}$ 의 입력작업에 사용하기 적합하지 않다. PDA를 이용하는 모바일 컴퓨팅 환경에는 작은 터치스 크린에 장착된 펜 입력시스템이 보다 적합한 입력수단이다 (Ren과 Moriya, 2000). 터치스크린을 이용하는 인터랙션은 다양한 인터랙션 방법들 중 가장 직접적인 인터랙션 방법이 다. 입력과 출력, 조작과 피드백, 손의 움직임과 눈의 움직임 에 있어서의 일치와 같은 특징들이 사용자가 터치스크린을 직관적으로 사용할 수 있게 한다(Albinsson과 Zhai, 2003).

$\mathrm{PDA}$ 에서의 입력은 크게 두 가지 방법으로 이루어진다. 첫째는 스타일러스 펜을 이용하여 화면상의 버튼 및 아이콘 과 같은 대상들을 선택하는 방식이고, 둘째는 필체인식 기술

*포항공과대학교 산업경영공학과, **포항공과대학교 컴퓨터공학과

교신저자: 박용성

주 소: 790-784 경북 포항시 남구 효자동 산31, 전화: 054-279-2855, E-mail: drastle@postech.ac.kr 
을 이용하여 화면상에 직접 글자나 기호를 입력하는 방식이 다. 두 방식 중, 첫 번째 방식이 두 번째 방식에 비해 보다 널리 사용된다(Ren과 Moriya; 2000). 그러나 스타일러스 펜을 이용하여 버튼을 선택하는 작업은 다음과 같은 문제점 들을 지닌다. 첫째, $\mathrm{PDA}$ 화면에 제공되는 버튼의 크기가 작 아 스타일러스 펜을 이용해 대상을 정확하게 선택하기 어렵 다(Ren과 Moriya; 2000). 둘째, 기존의 데스크탑 환경에 익숙한 사용자들에게 스타일러스 펜을 이용한 인터랙션 방 식이 익숙하지 않다. 셋째, 보는 각도에 따라 펜의 끝이 닿는 지점이 다르게 보임으로써, 정확한 대상을 선택하기 힘들다 (Greenstein, 1997).

이와 같은 입력작업의 문제점을 개선하기 위하여 많은 연 구들이 수행되었다. Ren과 Moriya(2000)는 펜을 이용하여 2 차원과 3 차원의 대상을 선택하는 작업을 상태모형(State Model)을 이용하여 설명하는 모델을 개발하고, 대상 선택 전략들을 개발, 비교 평가하였다. 또한 시스템상에 입력을 지원하는 방식을 구현함으로써 터치스크린 상에서 손을 이용 하여 작은 크기의 대상을 선택하는 작업을 개선하는 연구도 수행되었다(Albinsson과 Zhai, 2003). Aoki et al.(2001)는 펜 입력의 경우 마우스의 Hovering과 같은 작업을 수행할 수 없기 때문에, Tap-tip이라는 방식을 개발하여 사용자에 게 Tip을 제공하는 방식을 연구하였다. 또한 펜을 이용한 시 스템에서 버튼 선택을 통한 문자입력작업을 개선하기 위하 여 동작을 이용한 파이메뉴 형식의 키보드를 개발한 연구도 수행되었다(Mankoff과 Abowd, 1998). Matsushita et al. (2000)는 기존의 PDA 입력방식에 다른 손을 이용하는 인 터랙션을 추가하여 두 가지 입력을 받을 수 있는 시스템에 관한 연구를 수행하였고, McGee et al. (1998)은 PDA 시스 템에 적용이 가능한 multi-modal 인터랙션 시스템에 관한 연구를 수행하였다.

이와 같은 기존 연구들은 주로 펜 입력작업의 특성에 대한 연구(Ren과 Moriya, 2000)와 입력작업의 문제점을 해결하 기 위한 새로운 인터랙션 방식의 개발(Albinsson과 Zhai, 2003 Aoki et al., 2001; Mankoff과 Abowd, 1998; Matsushita et al., 2000; McGee et al., 1998 등) 로 구분될 수 있다. 그러나 펜 입력작업의 특성에 관한 연구는 기존의 버 튼 선택작업의 문제점을 해결하지 않고, 현재 상황에서 버튼 선택작업을 효과적으로 수행하는 방법에 관한 연구라는 특 징을 가진다. 또한 새로운 인터랙션 방식을 개발하는 연구들 은 개발된 인터랙션 방식이 사용자들에게 익숙하지 않아 사 용자들이 개발된 인터랙션 방식을 사용하기 어렵다는 한계 점을 가진다. 따라서 이러한 기존 연구들의 한계점들을 극복 하기 위하여, PDA 사용자에게 익숙한 방식을 이용하여 버튼 선택작업의 문제점을 해결할 수 있는 입력방식의 개발이 필 요하다.
본 연구는 기존의 사용자에게 익숙한 방식을 이용하여, 스타일러스 펜을 이용하여 PDA 화면 내 버튼을 선택하는 작업을 개선함으로써, 버튼 선택을 통한 입력작업의 사용성 (Usability)을 향상시키는 것을 목적으로 한다. 이를 위하여 본 연구에서는 버튼 선택작업에 대해 사용자들에게 익숙한 입력지원방식을 제안하고, 입력지원방식 이외에 버튼크기, $\mathrm{PDA}$ 사용경험 등과 같은 인자를 추가로 고려하여, 개발된 입력지원방식들의 사용성 비교 평가 실험을 실시하였다.

\section{2. 실험 방법}

\section{1 입력지원방식}

본 연구에서는 하이라이트 방식, 커서제공 방식, 확대방식 의 3 가지 방식을 버튼 선택작업을 위한 입력지원방식으로 개발하였다. 하이라이트 방식은 웹사이트에서 대상이 선택되 는 경우, 대상의 색상을 변경하여 선택여부를 사용자에게 제 공하는 방식이다. 본 연구에서는 스타일러스 펜이 버튼의 감 지영역 안에 들어가고, 스타일러스 펜의 좌표가 버튼의 영역 내에 위치하면 버튼의 색깔이 변함으로써, 사용자가 현재 스 타일러스 펜의 위치를 인식하는데 도움을 주도록 설계되었 다. 이때, 감지영역은 스타일러스 펜의 위치를 인식할 수 있 는 거리이다. 감지영역은 스타일러스 펜의 끝을 디스플레이 의 수직방향으로 투영 (projection)한 부분과 디스플레이와 의 거리를 통하여 측정된다(그림 1 참조). 본 연구에서 사용 한 감지영역은 약 $1.9 \mathrm{~cm}$ 이다.

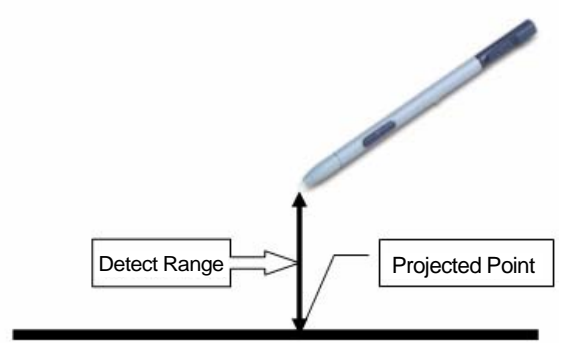

그림 1. 스타일러스 펜 감지영역

커서제공 방식은 스타일러스 펜이 감지영역안에 있을 때 스타일러스 펜의 좌표에 커서를 제공해주는 방식이다. 커서 제공 방식은 일반적인 $\mathrm{PC}$ 의 $\mathrm{GUI}$ 환경 상에서 마우스를 이 용한 입력작업에서 널리 사용되는 입력지원방식으로서 사용 자에게 친숙한 방식이다. 그림 2의 (a)와 (b)는 각각 하이 라이트 입력지원방식과 커서 입력지원방식을 나타낸다.

확대방식은 웹사이트에서 버튼의 선택여부를 사용자에게 제공하기 위하여 사용되는 방식으로써, 본 연구에서는 실험 


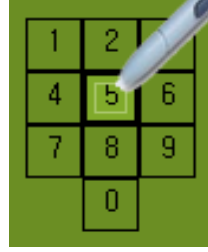

(a)

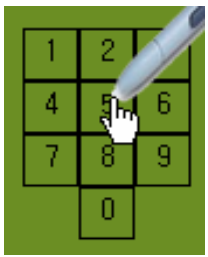

(b)

그림 2. 하이라이트 방식과 커서방식 (a: 하이라이트, b: 커서)

작업의 종류에 따라 구현한 확대방식이 다르다(각 실험작업 에 대한 상세한 설명은 2.4절 참조). 단일대상선택작업의 확 대방식은 스타일러스 펜이 감지영역으로 들어온 경우 스타 일러스 펜의 좌표 주변의 확대반경 $(1 \mathrm{~cm})$ 내에 있는 버튼을 2.25 배(가로, 세로 각 1.5 배) 확대시켜서 보여주는 방식이 다. 단문입력작업은 스타일러스 펜의 확대영역(가로, 세로 $1 \mathrm{~cm}$ 정사각형) 전체를 가로, 세로 각각 1.5 배 확대하여 보 여주는 방식을 사용한다. 그림 3(a)는 단일대상선택작업시 펜의 확대반경의 움직임에 따른 버튼의 확대방식을 나타낸 다. 그림 3(a)에 나타난 'A'는 정사각형 버튼의 폭을 나타내 고, 'b'는 버튼 위치의 기준점을 나타낸다. 또한 'R'은 스타일 러스 펜의 확대영역의 반지름을 나타낸다. 그림 3(b)는 단 문입력작업시 펜의 움직임에 따라 대상 버튼이 확대되는 예 를 나타낸다.
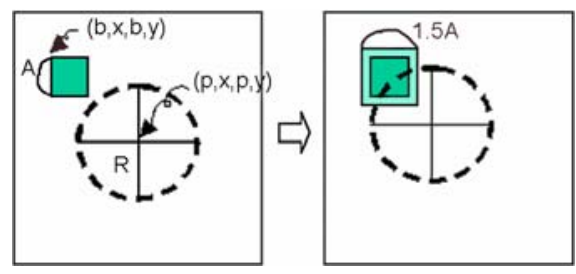

(a)

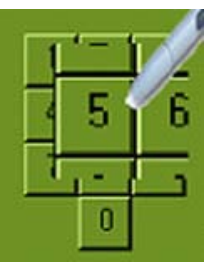

(b)
그림 3. 확대방식

(a: 단일대상선택작업 확대방식, $b$ : 단문입력작업 확대방식)

\section{2 피실험자}

총 16 명의 대학생이 실험에 참여하였다. 참가자들의 연령 은 18 세부터 23 세 사이였다 $($ 평균 $=21.2$, 표준편차 $=1.52$ ). 참가자 중 8 명은 펜을 이용한 인터랙션에 경험을 가진 반면, 8명은 펜을 이용한 인터랙션 경험이 없었다.

\section{3 실험기기}

본 연구에서 사용된 입력지원방식 중 커서제공 방식과
하이라이트 방식의 구현에는 Microsoft Visual Studio C\# .NET이 사용되었고, 확대방식은 Microsoft Visual $\mathrm{C}++6.0$ 을 사용하여 구현되었다. 구현된 입력지원방식들은 Tablet PC(Acer Travelmate C100)에 설치되어 실험에 사 용되었다.

$\mathrm{PDA}$ 를 이용하여 본 연구에서 제안된 입력지원방식을 구 현하는 경우, 작은 메모리 용량 및 낮은 $\mathrm{CPU}$ 성능과 같은 하드웨어 적인 이유로 구현된 입력지원방식이 적절히 작동 하지 않을 수 있다. Tablet PC는 이러한 PDA의 하드웨어적 인 문제를 해결할 수 있는 특징을 가진다. 또한 Tablet PC 는 PDA의 스타일러스 펜과 유사하게 펜을 이용하여 인터랙 션을 수행할 수 있는 특징을 가진다. 이와 같은 2 가지 이유 때문에 본 연구에서는 PDA 대신에 Tablet PC를 이용하여 실험을 수행하였다.

\section{4 수행작업}

본 실험의 실험 참가자들은 두 가지의 작업을 수행한다. 첫 번째 작업은 화면에 제시되는 하나의 버튼을 선택하는 작 업으로써, 단일대상선택작업으로 정의하였다. 단일대상선택 작업은 $\mathrm{PDA}$ 화면 하단의 시작 버튼을 누른 후 화면에 제시 되는 버튼을 누르는 작업이다.

두 번째 작업은 서로 인접한 여러 개의 버튼들로부터 원하 는 버튼을 선택하는 작업이다. 이 작업은 단문입력작업으로 정의하였다. 단문입력작업은 10 개의 숫자 버튼으로 이루어 진 숫자 패드의 버튼들을 클릭하여 화면에 제시되는 7자리 숫자를 입력하는 작업이다. 그림 4 (a)는 단일대상선택작업 의 실험을 위한 화면구성을 나타내고 그림 4(b)는 단문입력 작업의 실험을 위한 화면구성을 나타낸다.

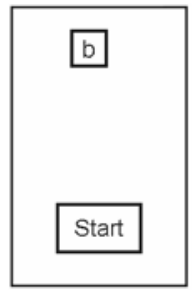

(a)

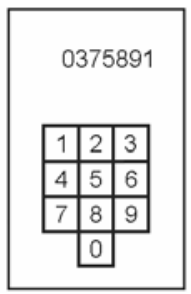

(b)
그림 4. 대상 작업별 작업 화면구성 (a: 단일대상선택작업, $\mathrm{b}$ : 단문입력작업)

\section{5 실험 디자인}

본 실험에서는 2 개의 Within-subjects 인자와 1 개의 Between-subjects 인자를 가지는 Mixed factor design이 
사용되었다. 두 개의 Within-subjects 인자는 각각 입력지 원방식과 버튼크기고 PDA 사용경험이 Between-subject 인자로 사용되었다. 입력지원방식은 4 가지의 인자수준(기본 방식, 버튼 확대방식, 하이라이트 방식, 커서제공 방식)을 가 진다. 이때 기본방식은 현재 PDA에서 사용되고 있는 방식 으로서, 시스템의 도움 없이 사용자가 펜을 이용하여 대상을 선택하는 방식이다. 가로와 세로의 길이가 각각 $12 \mathrm{Pixel}$ 과 18 Pixel인 두 가지 버튼크기가 버튼크기 인자의 수준으로 사용되었다. 12 Pixel과 18 Pixel은 각각 Samsung Nexio S151 Handheld PC와 Compaq iPaq 3660 Pocket PC에서 사용되는 버튼 중 가장 작은 버튼들의 크기와 유사한 크기 이다. PDA 사용경험 인자는 $\mathrm{PDA}$ 사용경험이 없는 경우와 $\mathrm{PDA}$ 사용경험이 있는 경우의 두 가지 수준으로 구분되었다.

\section{6 측정치}

2가지 종류의 측정치(수행도와 주관적 만족도) 가 본 연구 에서 측정되었다. 수행도는 작업수행시간과 에러 수의 두 가 지 측정치를 통하여 평가되었고, 주관적 만족도는 피실험자 가 느끼는 주관적 만족도의 Rating을 통해 평가되었다. $\mathrm{Ra}-$ ting 결과는 0점(매우 불편함) 과 100점(매우 편함) 사이의 점수를 갖도록 하였다.

단일대상선택작업의 경우, 작업수행시간과 주관적 만족도 를 측정하였다. 화면에 제시되는 대상 버튼의 위치는 실험프 로그램 상에서 무작위로 결정되었다. 이 경우, 작업수행시간 은 'Start' 버튼으로부터 대상 버튼까지의 거리에 밀접한 영 향을 받기 때문에, 단일대상선택작업의 작업수행시간은 화면 의 'Start' 버튼을 클릭한 후 화면에 제시되는 버튼을 클릭할 때까지의 시간을 'Start' 버튼에서 화면에 제시되는 버튼까지 의 거리로 나눈 값으로 정의하였다.

단문입력작업의 경우, 작업수행시간, 에러 수, 주관적 만족 도가 측정되었다. 작업수행시간은 7자리 숫자를 모두 올바르 게 입력하는데 소요된 시간을 의미하고, 에러 수는 7자리 숫 자를 입력하는 과정에서 잘못된 버튼을 누르는 횟수이다.

\section{7 실험 절차}

실험을 수행하기 전에 피실험자들에게 연구의 목적 및 실 험 절차를 설명한 후, 피실험자들이 펜과 터치스크린에 친숙 해지도록 하기 위해 Tablet PC를 자유롭게 사용하도록 하였 다. 또한, 본 실험이 시작하기 전에 사용자가 주관적 만족도 를 0점에서 100점 사이의 점수로 평가하는 작업에 익숙하 도록 충분한 연습을 실시하였다.

각각의 피실험자는 8 가지 실험조건(4가지 입력지원방식 $\times$ 2가지 버튼크기)에 대하여 단일대상선택작업과 단문입력작
업을 수행하였다. 각각의 실험조건에 대하여 단일대상선택작 업은 20회 반복 수행되었고, 단문입력작업은 7 회 반복 수행 되었다. 각각의 작업을 수행한 후에는 해당 실험조건에서 작 업을 수행할 때의 주관적 만족도를 평가토록 하였다. 실험조 건의 제시순서에 따른 효과를 방지하기 위하여 Latin-square balancing을 이용하여 실험순서를 결정하였다.

실험이 끝난 후에는 간단한 사후 설문조사를 실시하였다. 사후 설문에서는 입력지원방식의 주관적 만족도를 평가한 기준, 실험의 개선방안, 그리고 실험과정에서 느낀 점 등에 관한 피실험자의 의견을 수집하였다.

\section{3. 실험 결과}

실험을 통하여 수집된 측정치 중 작업수행시간과 주관적 만족도는 분산분석을 이용하여 분석되었고, 단문입력작업의 에러 수는 Kruskal-wallis test를 사용하여 분석되었다. 이 는 에러가 발생/미발생의 두 가지 상태만을 가지고 있고, 에 러의 발생이 특정한 분포를 따른다고 가정하기 어렵기 때문 이다(Hollander and Wolfe, 1973).

통계적으로 유의한 영향을 가지는 주 효과에 대해서는 Student Newman-Keuls(SNK) test를 통하여 통계적으로 유의한 주 효과의 수준간 평균차이를 분석하였으며, 통계적 으로 유의한 영향을 가지는 교호작용은 Simple effect test 를 통하여 그 효과를 추가적으로 분석하였다. 표 1은 단일대 상선택작업과 단문입력작업의 작업수행시간과 주관적 만족 도에 대한 분산분석 결과를 요약한 표이다.

표 1. 단일대상선택작업과 단문입력작업의 작업수행시간과 주관적 만족도에 대한 분산분석 결과 요약

\begin{tabular}{|c|c|c|c|c|}
\hline & \multicolumn{2}{|c|}{ 단일대상선택작업 } & \multicolumn{2}{|c|}{ 단문입력작업 } \\
\hline & $\begin{array}{l}\text { 작업수행 } \\
\text { 시간 }\end{array}$ & $\begin{array}{l}\text { 주관적 } \\
\text { 만족도 }\end{array}$ & $\begin{array}{l}\text { 작업수행 } \\
\text { 시간 }\end{array}$ & $\begin{array}{l}\text { 주관적 } \\
\text { 만족도 }\end{array}$ \\
\hline 입력지원방식 (A) & $<0.001^{*}$ & $0.001^{*}$ & $<0.001^{*}$ & $<0.001^{*}$ \\
\hline 버튼크기 (B) & $<0.001^{*}$ & $0.003^{*}$ & $0.021^{*}$ & $<0.001^{*}$ \\
\hline 사용경험 (C) & $0.022^{*}$ & 0.097 & 0.611 & 0.381 \\
\hline $\begin{array}{c}\text { 입력지원방식 } \times \text { 버튼크기 } \\
(\mathrm{A} \times \mathrm{B})\end{array}$ & $0.015^{*}$ & 0.141 & $0.004^{*}$ & 0.158 \\
\hline $\begin{array}{c}\text { 버튼크기 } \times \text { 사용경험 } \\
(\mathrm{B} \times \mathrm{C})\end{array}$ & 0.365 & 0.350 & $0.021^{*}$ & 0.076 \\
\hline $\begin{array}{c}\text { 입력지원방식 } \times \text { 버튼크기 } \\
\times \text { 사용경험 } \\
(\mathrm{A} \times \mathrm{B} \times \mathrm{C})\end{array}$ & 0.705 & 0.065 & 0.296 & $0.016^{*}$ \\
\hline
\end{tabular}

*유의수준 $\alpha=0.05$ 에서 유의한 효과 


\section{1 작업수행시간}

\section{1 .1 단일대상선택작업}

분산분석 결과, 입력지원방식, 버튼크기, $\mathrm{PDA}$ 사용경험 그 리고 입력지원방식과 버튼크기의 교호작용이 단일대상선택 작업의 작업수행시간에 통계적으로 유의한 영향을 미치는 것으로 나타났다 $(\mathrm{p}<0.05)$.

입력지원방식의 경우, 커서제공 방식은 다른 세 방식(기본 방식, 하이라이트 방식, 확대방식)보다 작업수행시간이 오래 걸렸다. 그림 5의 (a)는 커서방식을 제외한 세가지 입력방식 은 작업수행시간이 통계적으로 유의한 차이를 보이지 않음 을 나타낸다. 18 pixel 버튼이 12 pixel 버튼보다 작업수행시 간이 짧았다(그림 5의 (b) 참조). PDA 사용경험이 있는 피 실험자는 $\mathrm{PDA}$ 사용경험이 없는 피실험자보다 짧은 시간에 작업을 수행하였다(그림 5의 (c) 참조).

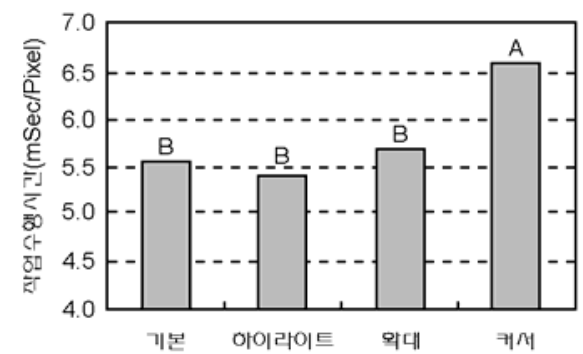

(a) 입력지원방식에 따른 작업수행시간

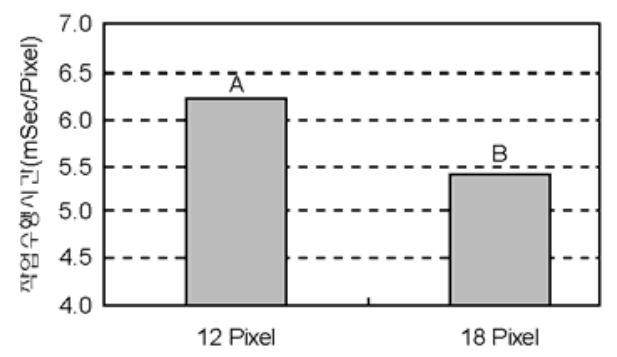

(b) 버튼크기에 따른 작업수행시간

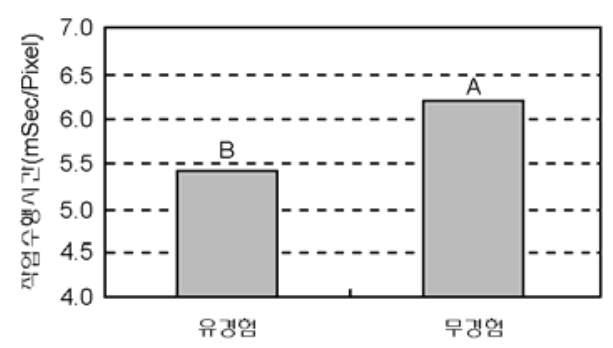

(c) PDA 사용경험에 따른 작업수행시간

그림 5. 단일대상선택작업수행시간 (A, B: 유의수준 0.05 에서 SNK 그룹핑 결과)
입력지원방식과 버튼크기의 교호작용에 대한 Simple effect test 결과, 기본방식 $(\mathrm{p}=0.037)$, 하이라이트 방식 $(\mathrm{p}=0.003)$, 커서제공 방식 $(\mathrm{p}=0.001)$ 에서는 버튼의 크기가 작업수행시 간에 통계적으로 유의한 영향을 미친 반면, 확대방식 $(\mathrm{p}=$ 0.726)에서는 버튼의 크기가 작업수행시간에 통계적으로 유 의한 영향을 미치지 않았다(그림 6참조).

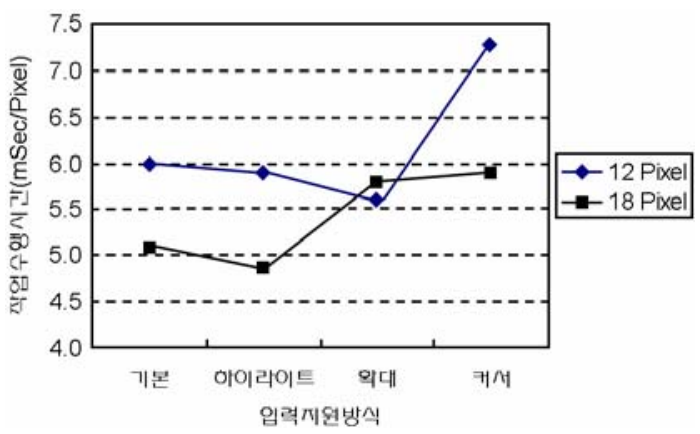

그림 6. 입력지원방식과 버튼크기에 따른 단일대상선택작업수행시간

\subsection{2 단문입력작업}

입력지원방식과 버튼크기의 주 효과와 입력지원방식과 버 튼크기의 교호작용, $\mathrm{PDA}$ 사용경험과 버튼크기의 교호작용 등 4 가지 효과가 단문입력작업의 작업수행시간에 통계적으

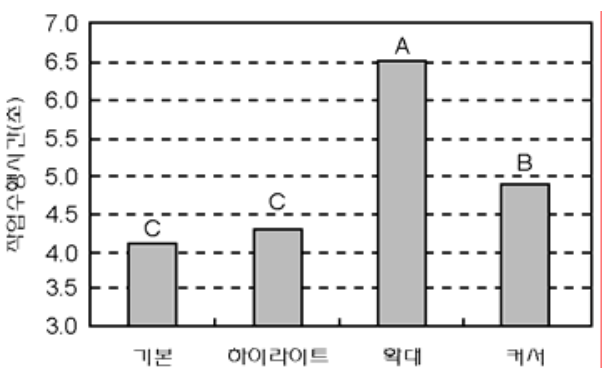

(a) 입력지원방식에 따른 작업수행시간

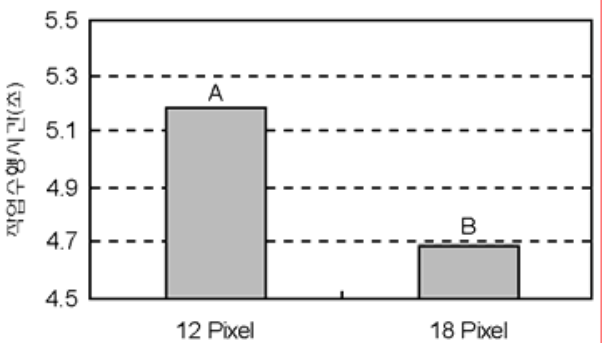

(b) 버튼크기에 따른 작업수행시간

그림 7. 단문입력작업수행시간

(A, B, C: 유의수준 0.05 에서 SNK 그룹핑 결과) 
로 유의한 영향을 미쳤다(표 1 참조). 입력지원방식 인자의 $\mathrm{SNK}$ 분석 결과, 기본방식과 하이라이트 방식의 작업수행시 간이 가장 짧았다. 다음으로 커서 제공방식이었고, 확대방식 의 작업수행시간이 가장 길었다. 버튼크기에 대한 $\mathrm{SNK}$ 분 석 결과는 18 pixel 버튼의 작업수행시간이 12 pixel 버튼의 작업수행시간보다 짧음을 보인다. 그림 7 은 입력지원방식과 버튼크기의 수준별 작업수행시간을 나타낸다.

입력지원방식과 버튼크기의 교호작용에 대한 simple effect test 결과, 기본 $(\mathrm{p}=0.019)$ 및 커서제공 $(\mathrm{p}=0.016)$ 방식은 버튼크기가 작업수행시간에 통계적으로 유의한 영향을 미친 반면, 하이라이트 $(\mathrm{p}=0.555)$ 방식과 커서방식 $(\mathrm{p}=0.430)$ 은 버튼크기가 통계적으로 유의한 영향을 미치지 않았다. 그림 8은 입력지원방식과 버튼크기에 따른 단문입력작업수행시간 을 보여준다.

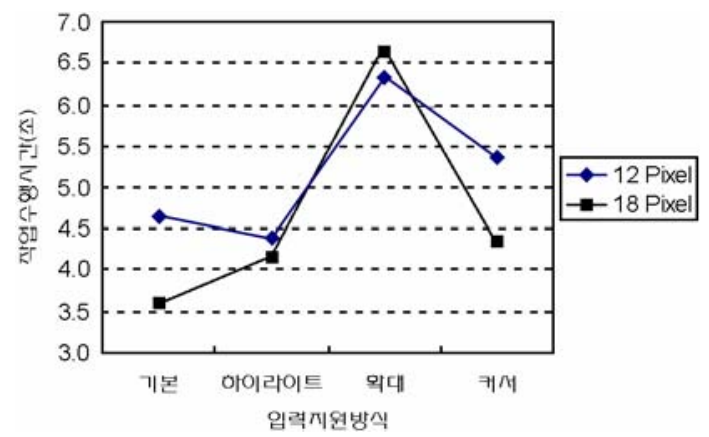

그림 8. 입력지원방식과 버튼크기에 따른 단문입력작업수행시간

$\mathrm{PDA}$ 사용경험과 버튼크기간의 교호작용에 대한 Simple effect test 결과, PDA 사용경험이 있는 경우 $(p=0.003)$ 는 버튼크기가 작업수행시간에 통계적으로 유의한 영향을 미친 반면, PDA 사용경험이 없는 경우는 통계적으로 유의한 영향 을 미치지 않았다. 그림 9는 PDA 사용경험과 버튼크기에 따른 단문입력작업수행시간을 나타낸다.

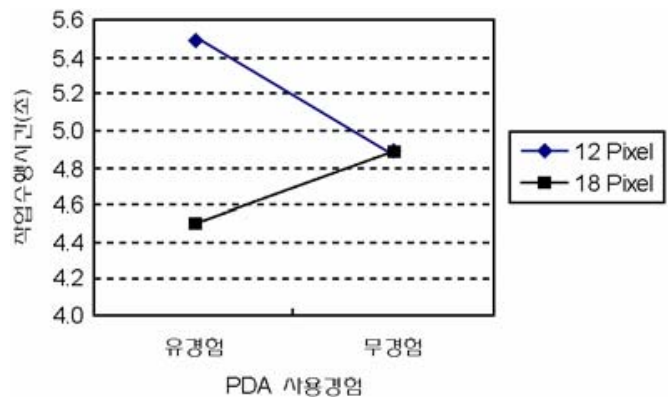

그림 9. PDA 사용경험과 버튼크기에 따른 단문입력작업수행시간

\section{2 주관적 만족도}

\subsection{1 단일대상선택작업}

표 1에 따르면, 입력지원방식과 버튼크기, 두 개의 주 효 과가 주관적 만족도에 유의한 영향을 미친다. 입력지원방식 에 대한 SNK 분석 결과, 확대방식의 주관적 만족도가 가장 높은 반면, 기본방식에 대한 주관적 만족도가 가장 낮았다. 커서방식과 하이라이트 방식의 주관적 만족도는 확대방식보 다 낮고, 기본방식보다 높은 수준이었다. 버튼크기에 대한 $\mathrm{SNK}$ 분석 결과는 $18 \mathrm{Pixel}$ 일 때의 주관적 만족도가 12 Pixel일 때의 주관적 만족도보다 높았다. 그림 10은 입력지 원방식과 버튼크기의 수준별 단일대상선택작업의 주관적 만 족도를 나타낸다.

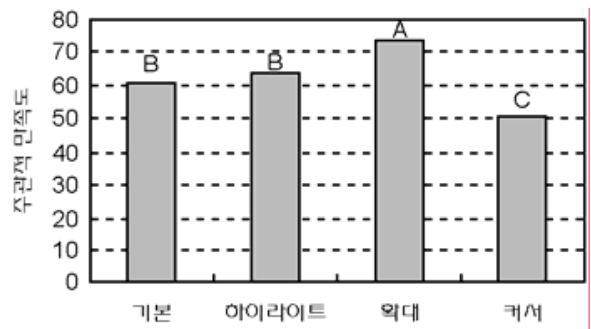

(a) 입력지원방식에 따른 주관적 만족도

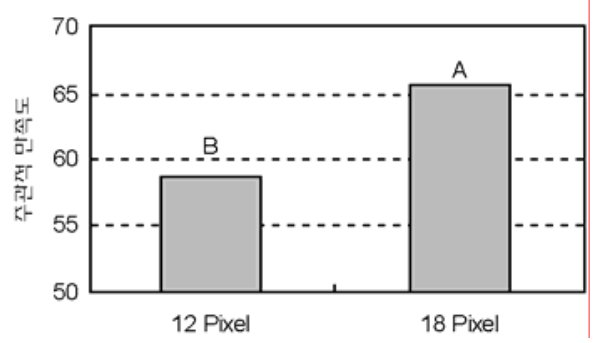

(b) 버튼크기에 따른 주관적 만족도

그림 10. 단일대상선택작업 주관적 만족도 (A, B, C: 유의수준 0.05 에서 SNK 그룹핑)

\subsection{2 단문입력작업}

단일대상선택작업과 같이, 입력지원방식과 버튼크기가 단 문입력작업의 주관적 만족도에 통계적으로 유의한 영향을 미쳤다(표 1 참조). 그림 11 은 단문입력작업의 주관적 만족 도 분석 결과를 나타낸다. 버튼크기에 대한 $\mathrm{SNK}$ 분석 결과 는 단일대상선택작업과 같다. 그러나 입력지원방식에 대한 $\mathrm{SNK}$ 분석 결과, 하이라이트 방식의 주관적 만족도가 가장 높고 다른 3 가지 방식에 따른 주관적 만족도는 통계적으로 유의한 차이를 보이지 않았다. 


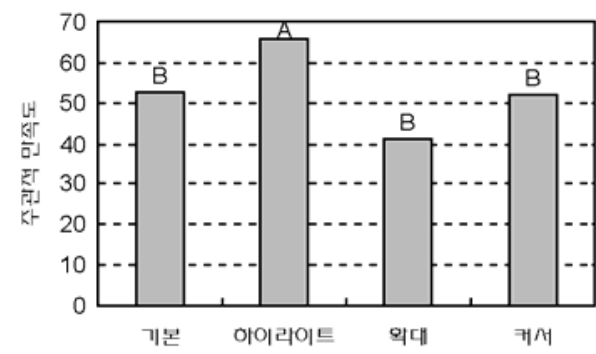

(a) 입력지원방식에 따른 주관적 만족도

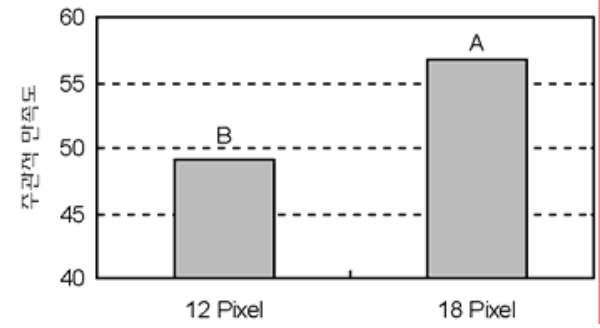

(b) 버튼크기에 따른 주관적 만족도

그림 11. 단문입력작업 주관적 만족도

(A, B: 유의수준 0.05 에서 SNK 그룹핑 결과)

\section{3 단문입력작업 에러 수}

표 2는 단문입력작업수행 시 버튼크기, 경험유무, 입력방 식의 에러 수에 대한 영향을 Kruskal-Wallis test를 이용하 여 분석한 결과이다. 에러 수는 입력지원방식 $(\mathrm{p}<0.001)$ 의 종류에 의하여 영향을 받지만, 버튼크기 $(\mathrm{p}=0.068)$ 와 사용 경험 $(\mathrm{p}=0.318)$ 에 의해서는 통계적으로 유의한 영향을 받지 않는다.

표 2. 에러 수에 대한 Kruskal-Wallis test 분석 결과

\begin{tabular}{cccc}
\hline 변수 & 자유도 & $\mathrm{H}$ 값 & $\mathrm{P}$ 값 \\
\hline 버튼크기 & 1 & 3.32 & 0.068 \\
\hline 입력지원방식 & 3 & 305.8 & $<0.001^{*}$ \\
\hline 사용경험 & 1 & 1 & 0.318 \\
\hline
\end{tabular}

*유의수준 $\alpha=0.05$ 에서 유의한 효과

그림 12 는 각 입력지원방식에 따라, 7 자리 단문입력작업 을 수행할 때 발생하는 평균 에러 수를 나타낸다. 기본방식 과 하이라이트 방식은 가장 낮은 에러 (에러 수=0.39) 가 발 생하고, 커서제공 방식은 약간 더 높은 에러(에러 수 $=0.42$ ) 가 발생하였다. 그러나 확대방식은 다른방식에 비해 많은 수 의 에러(에러 수 $=2.33$ )가 발생하였다.

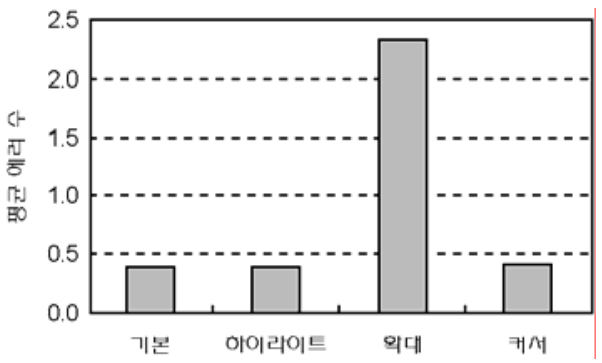

그림 12. 입력지원방식별 단문입력작업 에러 수

\section{4. 토 의}

\section{1 수행도}

\subsection{1 버튼의 크기}

본 연구 결과에 따르면 버튼의 크기가 증가함에 따라, 스 타일러스 펜을 이용하여 단일대상선택작업 및 단문입력작업 의 작업수행시간이 감소하였다. 비슷한 연구 결과로, Albinsson과 Zhai(2003)에 따르면 대상 버튼의 크기가 증가함 에 따라 데스크탑 환경에서 손을 이용하여 대상을 선택하는 작업의 작업수행시간이 감소한다. 이러한 결과는 작업수행시 간이 버튼의 폭(target width)에 반 비례하기 때문에 발생하 기 때문으로 분석된다(Fitts, 1954). 버튼의 크기 증가에 따 른 작업수행시간의 감소는 입력지원방식의 종류 및 해당 작 업의 종류에 따라 다르다(그림 6 , 그림 8 참조). 단일대상선 택작업의 경우, 확대방식을 제외한 기본, 하이라이트, 커서방 식을 사용할 때 버튼크기 증가에 따라 작업수행시간이 감소한 반면, 단문입력작업은 하이라이트 방식과 확대방식을 제외한 기본방식과 커서제공 방식일 때 버튼 확대에 따라 작업수행 시간이 감소하였다.

그러나, $\mathrm{PDA}$ 는 제한된 화면 크기 때문에, 화면에 제시할 수 있는 정보의 양이 작다(Ren과 Moriya, 2000). 버튼의 크기가 증가하는 경우 제한된 화면에 제시되는 정보의 양을 더욱 감소시킴으로써 $\mathrm{PDA}$ 의 사용성을 저하시킬 수 있다. 따라서, $\mathrm{PDA}$ 에서 펜을 사용하는 인터페이스를 디자인하는 과정에서 버튼의 크기 변화는 입력지원방식 및 수행작업 특 성에 따른 수행 시간 감소 효과, 화면 내의 정보량 변화 등 을 종합적으로 고려하여 결정되어야 한다.

\subsection{2 입력지원방식}

본 연구에서 제안된 3가지 입력지원방식(하이라이트, 확 대, 커서)은 사용자에게 익숙한 방식의 도움을 제공함으로써, 펜을 이용하여 대상을 선택하는 작업의 수행도를 향상시킬 수 있을 것으로 기대되었다. 그러나 사용성 평가 실험 결과, 
입력작업의 수행도를 개선시키지 못하였다(그림 5(a), 그림 7 (a) 참조).

스타일러스 펜을 이용하는 선택작업은 직접적인 눈과 손 의 협응동작(Eye-hand coordination)이다 (Albert, 1982). Neggers와 Bekkering (2001)에 따르면 협응동작은 saccade(빠른 안구 움직임), 손의 움직임 이전의 망막(retina) 을 통한 응시, 그리고 손/어깨의 움직임으로 구성되고 이들 은 각각 독립적이 아니라, 서로 연관성을 가지고 제어된다. 또한 전체적인 눈과 손의 협응동작은 계속적인 시각적 피드 백을 통하여 제어된다 (Neggers와 Bekkering, 2001).

커서방식의 경우, 제공된 커서가 현재 펜의 위치를 사용자 에게 효과적으로 제공함으로써, 작업수행시간을 감소시킬 것 으로 기대되었지만 실험분석 결과 두 가지 작업 모두에 대하 여 기본 방식보다 오랜 작업수행시간이 소요되었다(그림 5 (a), 그림 7(a) 참조), 사후 설문과정에서 피실험자들은 커 서의 크기가 너무 커서 사용하기에 불편하였다는 의견을 제 시하였다. 이러한 결과는 시각적 피드백으로써 제공된 커서 의 크기가 버튼에 비해 상대적으로 크기 때문에 현재 커서의 정확한 위치 및 커서가 위치한 버튼의 라벨을 확인하는 작업 을 수행하는 과정에서 추가적인 인지 부하를 야기하기 때문 에 발생하는 것으로 해석된다.

확대방식은 단문입력작업을 수행하는 경우 작업수행시간 이 가장 오래 걸렸다. 이러한 결과는 확대 알고리즘의 문제 때문인 것으로 해석할 수 있다. 그림 3(b)와 같이, 단문입력 작업에 사용된 확대방식은 스타일러스 펜의 확대반경 영역 을 확대하여 보여주는 것으로 확대방식이 돋보기와 유사한 역할을 수행한다(2.1절 참조). 이러한 확대방식은 확대된 영 역이 인접하는 버튼의 라벨을 가릴 수 있고, 확대영역이 움 직이는 경우 사용자에게 시각적인 부하를 야기하는 문제점 을 가지고 있다. 그림 3(b)의 경우, 0,5,6의 3가지 버튼을 제외한 다른 버튼들의 경우 라벨이 보이지 않음으로써, 작업 수행과정에서 사용자가 목표 버튼의 위치를 추측해야 하는 추가적인 인지부담을 발생 시킬 수 있다.

커서방식과 확대방식은 기존의 $\mathrm{PC}$ 운영 환경에서 화면 내 의 버튼을 선택하는 작업을 지원하는 방식으로 널리 사용되 고 있다. 그러나 이러한 방식들을 $\mathrm{PDA}$ 환경에 직접적으로 적용한 결과, 앞서 기술한 바와 같은 다양한 형태의 사용자 의 인지 부하를 야기함으로써 펜을 이용한 선택작업의 수행 도를 개선하지 못하였다. 이러한 차이점은 $\mathrm{PDA}$ 및 $\mathrm{PC}$ 환경 의 화면크기 차이에 의한 화면 내 버튼의 크기, 버튼 내 라 벨의 크기 및 위치, 버튼의 배치 등의 설계 요소가 다르기 때문으로 판단된다.

\subsubsection{PDA 사용경험}

일반적으로 $\mathrm{PDA}$ 사용경험을 가진 사용자는 펜을 이용한
인터랙션 방식을 경험해 보았기 때문에, $\mathrm{PDA}$ 사용경험이 없는 사용자에 비하여 작업수행시간이 짧을 것으로 기대된 다. 그러나 단문입력작업의 경우 버튼크기가 18 pixel인 경 우 유경험자의 작업수행시간이 더 빠르지만, 버튼의 크기가 12 pixel인 경우 무경험자의 작업수행시간이 유경험자의 작 업수행시간보다 빠른 결과가 도출되었다(그림 9 참조).

전체 작업수행시간은 작업수행과정에서 발생하는 에러에 의한 시간을 포함하기 때문에, 본 연구의 단문입력작업의 수 행시간은 작업수행시 발생하는 에러와 양의 상관관계를 가 지는 것으로 나타났다(상관계수 $\mathrm{r}=0.95$ ). 그림 13은 버튼 크기 및 경험 유무에 따른 단문입력작업수행의 에러 수를 나 타낸다. 버튼의 크기가 18 pixel인 경우, 무경험자의 에러 수 가 유경험자에 비해 높지만(무경험: 0.96, 유경험: 0.79), 버 튼의 크기가 12 pixel인 경우는 유경험자의 에러 수가 무경 험자의 에러 수보다 더 높다(무경험: 0.67, 유경험: 1.10). 즉 버튼의 크기가 12 pixel일 때, 에러 수에 의한 작업수행 시간 증가 효과는 사용경험에 따른 작업수행시간 감소 효과 보다 크기 때문에, 일반적인 예상과는 달리 무경험자의 작업 수행시간이 유경험자보다 빠른 것으로 유추된다.

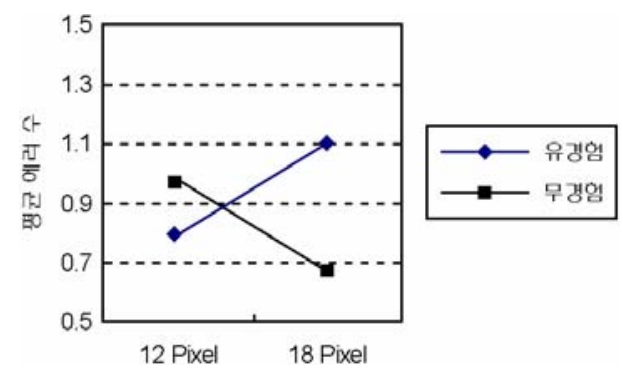

그림 13. 단문입력작업의 버튼크기 및 경험 유무에 따른 에러 수

\section{2 주관적 만족도}

본 연구에서 제안된 3 가지 입력지원방식은 수행도 측면에 서는 펜을 이용한 버튼 선택작업을 개선하지 못하였다(그림 5(a), 그림 7(a) 참조). 그러나 하이라이트 방식의 경우 주 관적 만족도 측면에서 두 가지 대상 작업 모두에 대하여 주 관적 만족도를 개선하였기 때문에, 추후 펜을 이용한 버튼 선택작업의 개선과정에서 우선적으로 고려될 수 있는 입력 지원방식이다(그림 10(a), 그림 11 참조). 커서제공 방식 및 확대방식은 단일대상선택작업의 경우에는 주관적 만족도를 향상시키지만, 단문입력작업의 경우에는 주관적 만족도를 향 상시키지 못하기 때문에 수행되는 작업의 유형에 따라 고려 될 수 있는 입력지원방식이다(그림 10(a), 그림 11 참조). 본 연구 결과에 따르면, 버튼크기가 클수록 주관적 만족도 
는 증가한다(그림 10 (b) 참조). 버튼의 크기는 작업수행과 정에서 요구되는 정확도를 나타내는 변수이다(Sanders와 McCormick, 1992). 따라서 버튼의 크기가 증가하면 작업 수행과정에서 요구되는 정확도가 감소하기 때문에 사용자의 주관적 만족도는 증가하는 결과가 발생한다.

그림 5(a), 7(a), 10(a), 11 및 그림 12에 따르면, 주관적 만족도는 작업수행시간 및 에러 수와 같은 수행도에 일정 수 준의 영향을 받지만, 이러한 수행도만을 이용하는 경우, 실 험 결과에서 도출된 주관적 만족도의 우선 순위에 대한 설명 이 충분하지 못하다. 이러한 연구 결과는 Nielson과 Levy (1994)의 연구 결과와 일치한다. Nielson과 Levy (1994) 따르면 전체 주관적 만족도 변화의 $21 \%$ 만이 수행도에 의해 설명되었고, 나머지 $79 \%$ 는 다른 요소에 의하여 설명되었지 만 해당 요소들이 무엇인지는 밝힐 수 없었다.

그러나 본 연구에서는 수행도 이외의 주관적 만족도에 영 향을 미치는 요인을 사후 설문 결과로부터 도출할 수 있었다. 피실험자들은 확대 알고리즘의 변화, 커서 크기 감소, 하이 라이트 색상의 변화 등과 같은 의견을 개선방향으로 제시하 였다. 이러한 사용자들의 의견들은 주관적 만족도에 영향을 미치는 요인들로 해석할 수 있다. 예를 들어, 커서의 상대적 크기를 감소시켜 커서방식을 구현하면, 사용자는 개선된 방 식에 더 큰 만족감을 느낄 것이기 때문에, 커서의 상대적 크 기는 본 연구에서 주관적 만족도에 영향을 미치는 인자로써 해석할 수 있을 것이다. 또한 기존에 사용되지 않았던 입력 지원방식의 구현이 신기하다는 답변도 있었는데, 이러한 경 우 구현된 기능의 참신성은 주관적 만족도에 영향을 미치는 인자로 해석될 수 있을 것이다.

\section{5. 결론 및 추후연구}

본 연구는 하이라이트, 커서제공, 확대 등 $\mathrm{PC}$ 환경에서 널 리 사용되는 3 가지 입력지원방식을 이용하여 $\mathrm{PDA}$ 환경에서 펜을 이용하여 대상을 선택하는 작업을 효과적으로 수행할 수 있도록 하는 것을 목적으로 수행되었다. 이를 위하여 총 16 명의 피 실험자가 참여하는 사용성 평가 실험을 통하여, 버튼크기, $\mathrm{PDA}$ 경험유무 그리고 입력지원방식이 스타일러스 펜을 이용한 버튼 선택작업에 미치는 영향을 분석하였다. 실 험 결과로부터 스타일러스 펜을 이용하여 버튼을 선택하는 작업의 사용성을 향상하기 위한 몇 가지 고려사항들이 다음 과 같이 도출되었다.

- 하이라이트 방식은 단일대상선택작업과 단문입력작업의 2
가지 작업유형에 적합한 개선안인 반면, 확대방식과 커서 방식은 단일대상선택작업에 적합한 개선방식이다.

- PDA 화면 내 버튼의 크기를 결정하기 위해서는, 입력지 원방식 및 수행작업의 종류, 버튼크기 변화에 따른 작업수 행시간의 변화, 주관적 만족도의 변화, 화면 내 정보량의 변화 등 다양한 요소들이 종합적으로 고려되어야 한다.

- 기존의 $\mathrm{PC}$ 환경의 입력지원방식을 $\mathrm{PDA}$ 환경에 적용하기 위해서는, $\mathrm{PC}$ 환경에서는 발생하지 않았지만, PDA 환경에 적용하는 과정에서 발생할 수 있는 사용자의 인지적 부하 에 대한 분석이 필요하다.

- 사용자에게 익숙한 입력지원방식은 버튼 선택작업의 수행 도를 향상시키지 못하더라도 사용자의 만족도를 향상시킬 수 있다.

- PDA 사용경험은 작업종류 및 버튼의 크기에 따라 버튼 선택작업의 에러 수 및 작업수행시간을 증가시킬 수 있다.

- 인터페이스 설계 과정에서 객관적인 사용성 평가 결과뿐 만 아니라, 사용자의 주관적인 의견들로부터 추출된 사용 성을 향상시키는 인자들에 대한 고려가 필요하다.

본 연구 결과는 $\mathrm{PDA}$ 의 버튼 선택작업에 영향을 미치는 요인들을 분석하고 $\mathrm{PDA}$ 인터페이스 설계 과정에서 고려하 여야 할 사항들을 제공함으로써, 추후 PDA의 사용성 향상 에 효과적으로 이용될 수 있을 것으로 기대된다.

그러나, 본 연구는 20대 대학생들을 대상으로 수행됨으로 써 $\mathrm{PDA}$ 의 사용인구가 다양한 연령대로 급속히 확대되는 현 상을 반영하지 못하였기 때문에, 추후에는 연구대상을 확대 함으로써 연령대에 따른 효과적인 입력지원방식에 대한 연 구가 필요하다.

\section{참고 문헌}

Aoki, P. M., Hurst, A. and Woodruff, A., "Tap Tips: Lightweight discovery of touchscreen targets", Proceedings of the ACM conference on Human Factors in Computing Systems-CHI 2001. Extended Abstracts (pp. 237-238), Seattle, WA, Apr. 2001,

Albert, A. E., "The effect of graphic input devices on performance in a cursor positioning task", Proceedings of the human factors society 26th annual meeting (pp. 54-58), Santa Monica, CA. 1982.

Albinsson, P. and Zhai, S., "High precision touch screen interaction." Proceedings of the ACM conference on Human Factors in Computing Systems-CHI 2003 (pp. 105-112), New York. 2003.

Fitts, P. M., The information capacity of the human motor system in controlling the amplitude of movement. Journal of Experimental Psychology, 47, 381-391, 1954 
Greenstein, J. S., Pointing devices. In Martin. G. Healander, Thomas K. Landauer, and Prasad V. Prabhu (Eds.), Handbook of human-computer interaction (2nd ed.), Elsevier, Amsterdam, 1997.

Hollander, M. and Wolfe, D. A., Nonparametric statistical methods, Wiley: New York, 1973.

Mankoff, J. and Abowd, G. D., Cirrin: A word-level unistroke keyboard for pen input. Proceedings of the ACM Symposium on User Interface Software and Technology (pp 213- 214), New York, 1998.

Marcus, A. and Chen, E., Designing the PDA of the future. Interactions, 9(1), pp. 34-44, 2002.

Matsushita, N., Ayatsuka, Y. and Rekimoto, J., Dual Touch: A two-handed interface for pen-based PDAs. CHI Letters, 2(2), pp. 211-212, 2000.

McGee, D., Cohen, P. R. and Oviatt, S. L., Confirmation in multimodal systems. Proceedings of Coling-ACL '98. Montreal: Association for Computational Linguistics. 1998.

Neggers, S. F. W. and Bekkering, H.,Gaze anchoring to a pointing target is present during the entire pointing movement and is driven by a nonvisual signal. Journal of Neurophysiology, 86(2), pp. 961-970, 2001.

Nielson, J. and Levy, J., Measuring usability: Preference vs. Performance. Communications of The ACM, 37(4), pp. 66-75, 1994.

Ren, X. and Moriya, S., Improving selection performance on pen-based systems: A study of Pen-based interaction for selection task. ACM Transactions on Computer-Human Interaction, 7(3), pp. 384-416, 2000.

Sanders, M. S. and McCormick, E. J., Human factors in engineering and design. McGraw-Hill: Singapore, 1992.
D 저자 소개

박 용 성 *

포항공과대학교 산업공학과 학사

현재 포항공과대학교 산업경영공학과 석 - 박사 통합과정 재학 중 관심 분야: User Interface Design, Affective Engineering, HCI

* 한 성 호*

서울대학교 산업공학과 학사, 석사

Virginia Polytechnic Institute and State University 산업공학과 박사 현재 포항공과대학교 산업경영공학과 교수

관심분야: User Interface Design, Affective Engineering, HCI

* 문 정 태 *

포항공과대학교 산업공학과 학사

현재 포항공과대학교 산업경영공학과 석 - 박사 통합과정 재학 중

관심분야: Intelligent Agent, 분산생산 시스템

* 전 석 희 *

포항공과대학교 컴퓨터공학과 학사

현재 포항공과대학교 컴퓨터공학과 석 - 박사 통합과정 재학 중 관심분야: Augmented Reality, Table-top Computing

논 문 접 수 일 (Date Received) : 2005년 01월 05일

논문게재승인일 (Date Acepted) : 2005년 08월 24일 